\title{
A Novel Colorimetric Immunoassay of Ultrasensitive Alpha-Fetoprotein Sensing in Magnetic Bead-Based Mimic Enzyme-Chromogenic Substrate System
}

\author{
Dan Su, ${ }^{a}$ Qiang Zeng, ${ }^{a}$ Bingwei Feng, ${ }^{a}$ Pengfei Xu, ${ }^{a}$ Baixi Shan ${ }^{a}$ and Yonggui Song ${ }^{\oplus}, a$ \\ ${ }^{a}$ Jiangxi University of Traditional Chinese Medicine, 1688 Meiling Road, 330006 Nanchang, China
}

\begin{abstract}
This work described a simple and feasible colorimetric immunoassay. Using hemin (a horseradish peroxidase (HRP) mimic enzyme) and the mimic enzyme-chromogenic substrate system, it can qualitatively and quantitatively detect $\alpha$-fetoprotein (AFP) at an ultralow concentration. The glucose oxidase (GOx) catalyzed oxidation of glucose leads to the formation of gluconic acid and hydrogen peroxide $\left(\mathrm{H}_{2} \mathrm{O}_{2}\right)$. The latter can oxidize 4-aminoatipyrine (4-AAP) to chromogenic products, and the reaction was catalyzed by hemin. With the increase of $\mathrm{H}_{2} \mathrm{O}_{2}$, the absorbance increased, and the color of the solution changed from colorless to pink. On the basis of the system, monitored by recording the color or absorbance $(\lambda=505 \mathrm{~nm})$, a new immunoassay protocol with GOx-labeled anti-AFP detection antibody was designed. A wide linear dependence was obtained in the range from 0.075 to $280 \mathrm{ng} \mathrm{mL}^{-1}$ with a low detection limit (LOD) of $0.0247 \mathrm{ng} \mathrm{mL}^{-1}(\mathrm{~S} / \mathrm{N}=3)$.
\end{abstract}

Keywords: magnetic bead, mimic enzyme, AFP, colorimetric immunoassay, hemin

\section{Introduction}

According to the most recent data from the Chinese Anti-Cancer Association, ${ }^{1-3}$ cancer is the most common cause of death in China and nearly 6000 people die of cancer every day in this country. Globally, cancer is set to become one of the main causes of morbidity and mortality in the coming decades in all regions of the world, regardless of the level of resources. Given this serious situation, the sensitive detection of cancer biomarkers is becoming increasingly significant for early clinical diagnosis, disease prevention, and biomedical research. ${ }^{4,5}$ Significant progress has been made in the detection of disease biomarkers utilized by, for example, electrochemistry, ${ }^{6-8}$ fluorescence, ${ }^{9,10}$ luminescence, ${ }^{11,12}$ microfluidic chips, ${ }^{13}$ naked eye detection, ${ }^{14,15}$ and surface plasmon resonance sensors. ${ }^{16}$ Along with the development of biotechnology, immunological method has become the predominant analytical tool for quantitative monitoring of low-abundance proteins by the sophisticated techniques involving surface plasmon resonance, ${ }^{17,18}$ quartz crystal microbalance, ${ }^{19}$ surface-enhanced Raman spectroscopy, ${ }^{20}$ fluorescence, ${ }^{21,22}$ electrochemistry, ${ }^{23}$ chemiluminescence ${ }^{24}$ and colorimetric assay. ${ }^{25}$ Among these methods, based on a specific antigen-antibody interaction, enzyme-linked

*e-mail: songyonggui1999@163.com immunosorbent assay (ELISA) is a very powerful technique because it can determine clinically important analyte in a variety of biological matrices. ${ }^{26,27}$ Usually, high sensitivity for the ELISA was achieved by using an indicator system that results in the amplification of the measurable product, e.g., enzyme labels or nanolabels. ${ }^{28,29}$

Undoubtedly, enzyme labels were utilized more widely than other labeling strategies, since a single enzymatic molecule, e.g., horseradish peroxidase (HRP), can cause the conversion of $10^{7}$ substrate molecules per minute. ${ }^{30}$ Meanwhile, using $\mathrm{H}_{2} \mathrm{O}_{2}$ as substrate, HRP can catalyze the oxidation of numerous hydrogen donors $\left(\mathrm{DH}_{2}\right){ }^{31}$ Despite some advances in this field, they have some limitations, such as the expensive protease like HRP, harsh reaction conditions, short period of stability and lack of the easy operation methods to make combination of visual qualitative identification and quantitative analysis. Thus, with the aim of manufacturing portable and affordable diagnostic devices, it is very critical to exploit new clinical immunoassay schemes and protocols for simultaneous quantitative and qualitative analysis.

To solve the above problems, a mimic enzymechromogenic substrate-based colorimetric immunoassay (MECI) has been designed in some works, ${ }^{32,33}$ which used hemin instead of HRP to catalyze hydrogen peroxide and to simultaneously produce a color reaction. The results showed that the catalytic activity of hemin can match with HRP, 
and it also has the advantages of low cost, good stability of the physical and chemical properties, easy preservation and relaxed reaction conditions. However, their operation steps are very complicated, especially the synthesis of composite nanomaterials and the immobilization of protein. ${ }^{32,33}$ Moreover, the immobilized materials like metal-organic frameworks (MOFs), which have many metal sites, may increase the toxicity to the immobilized enzymes and antibodies, and were not conducive to the biochemical reactions. Herein, a magnetic immunosensing probe by using polyclonal anti- $\alpha$-fetoprotein (AFP)/glucose oxidase (GOx)-labeled gold nanoparticle (AuNP) as the signaltransduction tag with a sandwich-type immunoassay format has been designed. Compared with other nanomaterials, gold nanoparticles have good biocompatibility and simple synthesis procedure. Moreover, there are a large number of thiol groups of protein molecules which are easily adsorbed to AuNPs surface through $\mathrm{Au}-\mathrm{S}$ bond. Therefore, antibodies and enzymes can be more firmly immobilized on AuNPs. To model the MECI in terms of immunoreactions, AFP was employed as our target analyte, with mouse immunoglobulin $\mathrm{M}(\mathrm{IgM})$ and rabbit immunoglobulin $\mathrm{G}$ $(\mathrm{IgG})$ as the capture and detection antibodies, respectively. $\alpha$-Fetoprotein (AFP) is the best indicator of the diagnosis of primary liver cancer. According to the relevant literature, ${ }^{34}$ the primary liver cancer can be diagnosed in the first 6-12 months before appearing clinical symptoms by the application of this index. Herein, the assay was carried out on a magnetic immunosensing probe by using polyclonal anti-AFP/GOx-labeled gold nanoparticle as the signaltransduction tag with a sandwich-type immunoassay format. In the presence of target AFP, the carried GOx accompanying the sandwiched immunocomplex initially catalyzes glucose to gluconic acid and hydrogen peroxide, and then the regenerated hydrogen peroxide is catalyzed by the HRP mimic enzyme-hemin to produce the colored product. By monitoring the change in the visible color or UV absorbance, the target AFP were not only qualitatively judged, but also quantitatively determined in the sample with wide linear range, low detection limit (LOD), high selectivity and long-term stability. Meanwhile, the handy operational MECI has good accuracy to detect AFP in real serum.

\section{Experimental}

\section{Materials and reagents}

Rabbit IgG (RIgG), mouse IgM (MIgM), and AFP were purchased from Shanghai Yemin Biotech, Inc. (Shanghai, China). 3-Aminopropyltriethoxysilane (APTES, 98 wt.\%), hemin and GOx were provided from Sigma-Aldrich (Shanghai, China). Glucose was purchased from Alfa Aesar (Shanghai, China). Bovine serum albumin (BSA) was obtained from Sinopharm Chemical Reagent Co., Ltd. (Shanghai, China). 4-Aminoantipyrine (4-AAP), phenol and glutaraldehyde ( $25 \mathrm{wt} . \%$ ) were obtained from Fuchen Chemicals (Tianjin, China). Colloidal gold (AuNP) with $15 \mathrm{~nm}$ diameter was synthesized according to our previous report. ${ }^{35}$ Magnetic beads (MB; particle size ca. $100 \mathrm{~nm}$ ) in an aqueous suspension with a concentration of $25 \mathrm{mg} \mathrm{mL}^{-1}$ were obtained from Chemical GmbH (Berlin, Germany). All reagents used for all experiments were of analytical grade and were used without further purification. Ultrapure water $(18.2 \mathrm{M} \Omega \mathrm{cm})$ was purified by a Millipore-Q system (Jingyixingye Science and Technology Co., Ltd, Xiamen, China). In the preparation of a carbonate buffer of $\mathrm{pH} 9.6$, $\mathrm{Na}_{2} \mathrm{CO}_{3}(1.59 \mathrm{~g}), \mathrm{NaHCO}_{3}(2.93 \mathrm{~g})$, and $\mathrm{NaN}_{3}(0.2 \mathrm{~g})$ were dissolved in $1000 \mathrm{~mL}$ of double-distilled water. Phosphate-buffered saline (PBS) solutions with various $\mathrm{pH}$ values were prepared by using $\mathrm{Na}_{2} \mathrm{HPO}_{4}$ and $\mathrm{KH}_{2} \mathrm{PO}_{4}$, and $0.1 \mathrm{M} \mathrm{NaCl}$ was used as the supporting electrolyte. Clinical serum samples were made available by Jiangxi Provincial Hospital of traditional Chinese Medicine (China). All experiments were in accordance with the guidelines of the National Institute of Food and Drug (Nanchang, China), and approved by the institutional ethical committee (IEC) of Jiangxi University of Traditional Chinese Medicine.

\section{Preparation of MlgM-MB conjugates}

Before conjugation with MIgM, the magnetic bead was initially separated using an external magnet and then dried in the vacuum at $80{ }^{\circ} \mathrm{C}$ for $1 \mathrm{~h}$. Following that, $50 \mathrm{mg}$ of MB was added into $1 \mathrm{~mL}$ of anhydrous ethanol and the resulting mixture was sonicated for $10 \mathrm{~min}$ at room temperature (RT) to obtain a homogeneous suspension. Afterward, $30 \mu \mathrm{L}$ of APTES (98 wt.\%) was injected in the mixture and continuously stirred for $6 \mathrm{~h}$ at RT. During this process, the aminated MB was formed based on the reaction between $-\mathrm{OCH}_{3}$ and $-\mathrm{OH}$ on the $\mathrm{MB}$. The functional $\mathrm{MB}$ was separated and redispersed into $1 \mathrm{~mL}$ of PBS (pH 7.4) containing $300 \mu \mathrm{L}$ of glutaraldehyde (25 wt.\%). The suspension was stirred vigorously for $6 \mathrm{~h}$ at RT. After magnetic separation, the precipitate was dissolved into $1 \mathrm{~mL}$ of carbonate buffer ( $\mathrm{pH}$ 9.6) containing $100 \mu \mathrm{g}$ of MIgM antibody and shaken on an IKA MS shaker (GmbH, Staufen, Germany) overnight at $4{ }^{\circ} \mathrm{C}$. The excess MIgM antibody was removed by magnetic separation. Subsequently, the MIgM-MB conjugates were treated with $10 \mathrm{wt} . \%$ BSA-PBS $(1.0 \mathrm{~mL}, \mathrm{pH} 7.4)$ at $4{ }^{\circ} \mathrm{C}$ for $2 \mathrm{~h}$ to block the unreacted and nonspecific sites. Finally, $100 \mu \mathrm{L}$ of 
sodium cyanoborohydride $\left(25 \mathrm{mg} \mathrm{mL}^{-1}\right)$ was injected into the suspension in order to reduce the resultant Schiff bases. The MIgM-MIgM conjugates were collected by using an external magnet and dispersed into $1 \mathrm{~mL}$ of PBS (pH 7.4) containing $1.0 \mathrm{wt} . \% \mathrm{BSA}$ and $0.1 \mathrm{wt} . \%$ sodium azide.

Preparation of GOx/RlgG-conjugated gold nano-particle (GOx-AuNP-RIgG)

Prior to labeling, the gold colloids (AuNP, gold concentration $\left(\mathrm{C}_{[\mathrm{Au}]}\right)$ ca. $\left.0.24 \mu \mathrm{M}\right)$ with $15 \mathrm{~nm}$ in diameter were initially adjusted to $\mathrm{pH} 9.0-9.5$ by directly using $0.1 \mathrm{M}$ $\mathrm{Na}_{2} \mathrm{CO}_{3}$ aqueous solution. With gentle stirring, the mixture containing $1.0 \mu \mathrm{L}$ of $\operatorname{RIgG}\left(1.0 \mathrm{mg} \mathrm{mL}^{-1}\right)$ and $10 \mu \mathrm{L}$ of GOx $\left(1.0 \mathrm{mg} \mathrm{mL}^{-1}\right)$ was added into $1.0 \mathrm{~mL}$ of colloidal gold. After incubation overnight at $4{ }^{\circ} \mathrm{C}$, the mixture was centrifuged $(14000 \times \mathrm{g})$ for $20 \mathrm{~min}$ at $4{ }^{\circ} \mathrm{C}$. The pellet (i.e., GOx-AuNP-RIgG) was resuspended into $1.0 \mathrm{~mL}$ of sodium carbonate solution $(2 \mathrm{mM})$ containing $1.0 \mathrm{wt} . \% \mathrm{BSA}$ and $0.1 \%$ sodium azide, $\mathrm{pH} 7.4$, and stored at $4{ }^{\circ} \mathrm{C}$ until use.

Monitoring of GOx activity using the hemin/4-AAP/phenol system

Figure 1a displays the assay mechanism of the hemin/4-AAP/phenol system. Initially, $10 \mu \mathrm{L}$ of GOx with specified concentration (from 0 to $1000 \mu \mathrm{g} \mathrm{mL}^{-1}$ ) was added in $50 \mu \mathrm{L}$ of PBS $(0.5 \mathrm{mM}, \mathrm{pH} 7.0)$ containing $4 \mathrm{mM}$ glucose. The resulting solution was incubated for $30 \mathrm{~min}$ at $37{ }^{\circ} \mathrm{C}$. Then $70 \mu \mathrm{L}$ of $0.1 \% 4-\mathrm{AAP}, 70 \mu \mathrm{L}$ of $0.123 \mathrm{M}$ phenol, $35 \mu \mathrm{L}$ of $0.05 \mathrm{mg} \mathrm{mL}^{-1}$ heme chloride solution and $350 \mu \mathrm{L}$ buffer $\left(\mathrm{K}_{2} \mathrm{HPO}_{4}: \mathrm{NaOH}, \mathrm{pH}=10.6\right)$ was added into the above-prepared mixture and reacted for $10 \mathrm{~min}$ at room temperature. After interaction, the color of the solution was observed and at the same time the absorbance was recorded at $\lambda=505 \mathrm{~nm}$ on a Lambda $35 \mathrm{UV}$-Vis spectrophotometer (Richmond Scientific Ltd., Lancashire, UK).

Immunoassay for target AFP using the mimic enzymechromogenic substrate system

Figure $1 \mathrm{~b}$ represents the immunoassay process toward target AFP by coupling with the hemin/4-AAP/phenol system. The detailed procedure was summarized as follows: (i) $50 \mu \mathrm{L}$ of AFP standards or samples with different concentrations and $25 \mu \mathrm{L}$ of MB-MIgM suspension (6 mg mL $\mathrm{mL}^{-1}$ ) were initially added into a $0.5 \mathrm{~mL}$ centrifuge tube, and the mixture was then incubated for $30 \mathrm{~min}$ at $37{ }^{\circ} \mathrm{C}$ on a shaker to form the antigen-antibody complex; (ii) $50 \mu \mathrm{L}$ of GOx-AuNP-RIgG prepared above was injected into the centrifuge tube and incubated for another $30 \mathrm{~min}$ at (a)

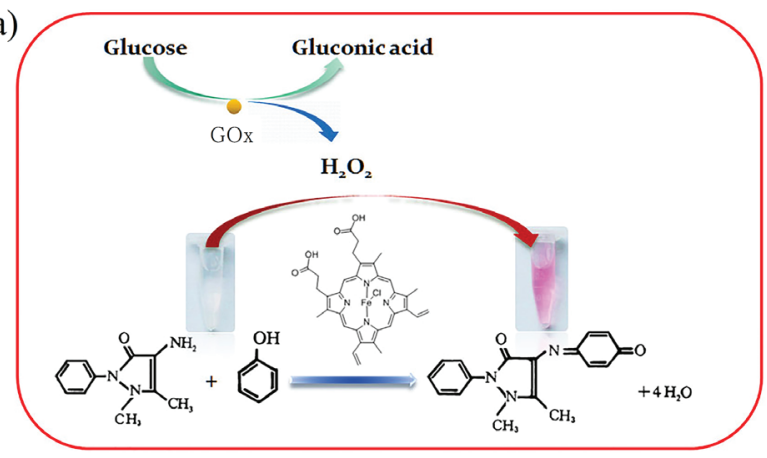

(b)

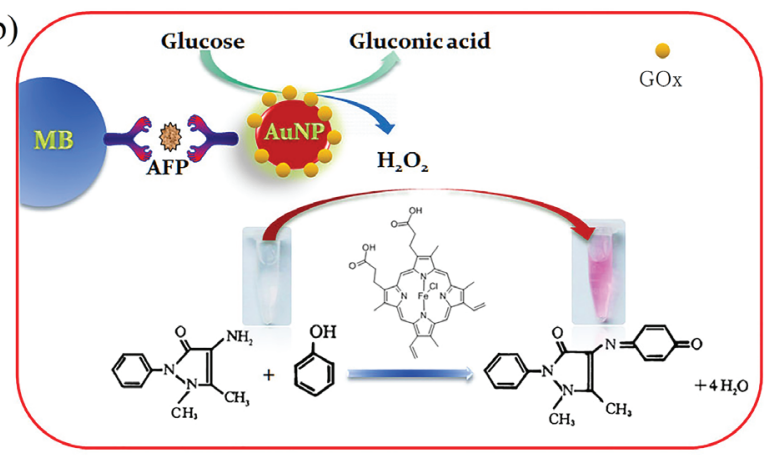

Figure 1. Schematic illustration of (a) $\mathrm{H}_{2} \mathrm{O}_{2}$-stimulated colorimetric assay for monitoring of GOx activity and (b) MECI by coupling with the hemin/4-AAP/phenol system (MB: magnetic beads with $100 \mathrm{~nm}$ in diameter; AuNP: gold nanoparticle with $15 \mathrm{~nm}$ in diameter).

$4{ }^{\circ} \mathrm{C}$ to form the sandwiched immunocomplex; (iii) $50 \mu \mathrm{L}$ of glucose $(4 \mathrm{mM})$ in $\mathrm{pH}$ 7.0 PBS was added into the centrifuge tube and incubated for $30 \mathrm{~min}$ at $37^{\circ} \mathrm{C}$ on the shaker for enzymatic reaction; (iv) $70 \mu \mathrm{L}$ of $1.0 \mathrm{mg} \mathrm{mL}^{-1}$ 4-AAP, $70 \mu \mathrm{L}$ of $0.12 \mathrm{M}$ phenol, $35 \mu \mathrm{L}$ of $0.05 \mathrm{mg} \mathrm{mL}^{-1}$ heme chloride solution and $350 \mu \mathrm{L}$ buffer $\left(\mathrm{K}_{2} \mathrm{HPO}_{4}: \mathrm{NaOH}\right.$, $\mathrm{pH}=10.6$ ) were added to the centrifuge tube in turn; and $(v)$ the color of the solution was observed and at the same time the absorbance was registered and recorded at $\lambda=505 \mathrm{~nm}$ on a Lambda $35 \mathrm{UV}$-Vis spectrophotometer (Richmond Scientific Ltd., Lancashire, UK) at room temperature (the resulting mixture was separated with an external magnet and washed with pH 7.4 PBS after steps (i) and (ii). The control tests with normal (negative) samples and the evaluations for clinical specimens were performed accordingly. All measurements were done at room temperature $\left(25 \pm 1.0^{\circ} \mathrm{C}\right)$ ).

\section{Results and Discussion}

\section{Principle of the $\mathrm{MECl}$}

In this work, MIgM was immobilized on the MB by using glutaraldehyde as cross-linkage reagent (MIgM-MB), which was used as the immunosensing probe for the capture of target AFP. MB was not only used as a substrate for the 
conjugation of MIgM antibody, but also was used to enable the rapid separation and purification of bionanocomposites after synthesis. Gold nanoparticles heavily functionalized with GOx and RIgG antibody (GOx-AuNP-RIgG) was formed possibly due to the dative binding between AuNP and free $-\mathrm{SH}$ of the proteins. The GOx-AuNP-RIgG was employed as the signal-transduction tag (detection antibody) for the construction of the MECI. In the presence of target AFP, the sandwiched immune-conjugates can be formed between MB-MIgM and GOx-AuNP-RIgG. Accompanying the GOx-AuNP-RIgG, the carried GOx can trigger the enzymatic catalytic reaction to produce the colored product. Initially, the GOx-biocatalyzed oxidization toward the added glucose leads to the formation of gluconic acid and hydrogen peroxide $\left(\mathrm{H}_{2} \mathrm{O}_{2}\right)$ with the participation of oxygen. The generated hydrogen peroxide was catalyzed by hemin in the 4-AAP and phenol solution to produce the colored product, which turns the solution from colorless to pink. The change in the color/absorbance indirectly depends on the concentration of target AFP in the sample. By monitoring the shift in the absorbance, the concentration of target AFP was quantitatively determined in the sample. Vice versa, the AFP level was qualitatively judged by evaluating the change in the visible color. In contrast, GOx-AuNP-RIgG cannot be conjugated onto the functionalized MIgM-MB in the absence of target AFP; therefore, it cannot trigger the progression of MECI.

\section{Control tests for the $\mathrm{MECl}$}

For the successful development of MECI, one of the very important preconditions was whether the hemin/4-AAP/ phenol system was smoothly progressed in the presence of GOx, as depicted in Figure 1a. To demonstrate this concern, several relative control tests were put into effect under the different conditions by using UV-Vis absorption

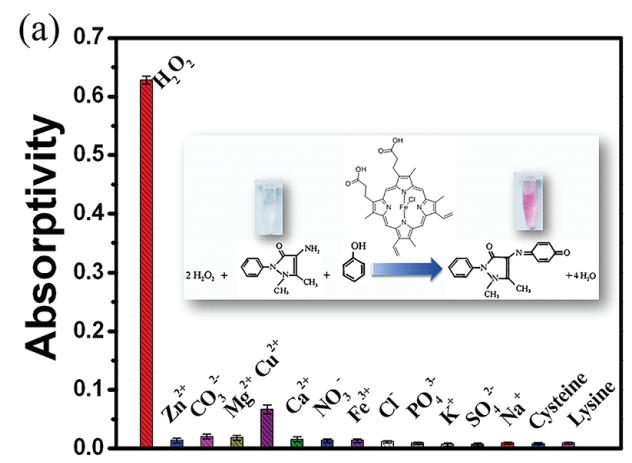

spectroscopy (Figure S1, Supplementary Information (SI) section) and the colorimetric measurement (see the illustration of Figure S1) $\left(10 \mu \mathrm{L}\right.$ of $1 \mathrm{mg} \mathrm{mL}^{-1} \mathrm{GOx}, 50 \mu \mathrm{L}$ of $1 \mathrm{mM}$ glucose, $70 \mu \mathrm{L}$ of $1.0 \mathrm{mg} \mathrm{mL}^{-1} 4$-AAP, $70 \mu \mathrm{L}$ of $0.12 \mathrm{M}$ phenol, $35 \mu \mathrm{L}$ of $0.05 \mathrm{mg} \mathrm{mL}^{-1}$ heme chloride solution and $350 \mu \mathrm{L}$ buffer $\left(\mathrm{K}_{2} \mathrm{HPO}_{4}: \mathrm{NaOH}, \mathrm{pH}=10.6\right)$ were used in this case, respectively). As shown from curve a in Figure S1 (SI section), a strong absorbance peak at $505 \mathrm{~nm}$ was observed after the added GOx reacted with the mixture containing glucose, hemin, 4-AAP and phenol. The reason might be that $\mathrm{H}_{2} \mathrm{O}_{2}$ formed a dye compound through the catalytic reaction of enzymatic product oxidized 4-AAP. Moreover, the newly formed dye compound can cause the change in the color of the mixed solution from the colorless to pink (photograph a in Figure S1). Further, it is found that the absorbance increased with the increasing GOx concentration under the same conditions (Figure 2). To further investigate the feasibility of the immunoassay system, the UV-Vis absorption spectroscopy and the visible color of different components were investigated in the absence of GOx, glucose, hemin, or 4-AAP. For comparison, the mixture containing GOx, glucose, and hemin was initially monitored. (i.e., in the absence of 4-AAP). As seen from curve $\mathrm{c}$ in Figure S1 (SI section), no absorption peak appeared at $505 \mathrm{~nm}$. Meanwhile, the mixture was colorless (photograph $\mathrm{c}$ in the inset of Figure S1). Favorably, when glucose (curve b in Figure S1 and photograph $b$ in the inset of Figure S1), hemin (curve d in Figure S1 and photograph $d$ in the inset of Figure S1), or GOx (curve e in Figure S1 and photograph e in the inset of Figure S1) was absent in the detection system, the absorption peak and the color were almost the same as that of curve $\mathrm{c}$ and photograph c, respectively. The results revealed that (i) hemin cannot cause the appearance of the absorption peak at $505 \mathrm{~nm}$ after incubation with the 4-AAP/phenol system without $\mathrm{H}_{2} \mathrm{O}_{2}$; (ii) $\mathrm{H}_{2} \mathrm{O}_{2}$ was provided by $\mathrm{GOx}$ toward the

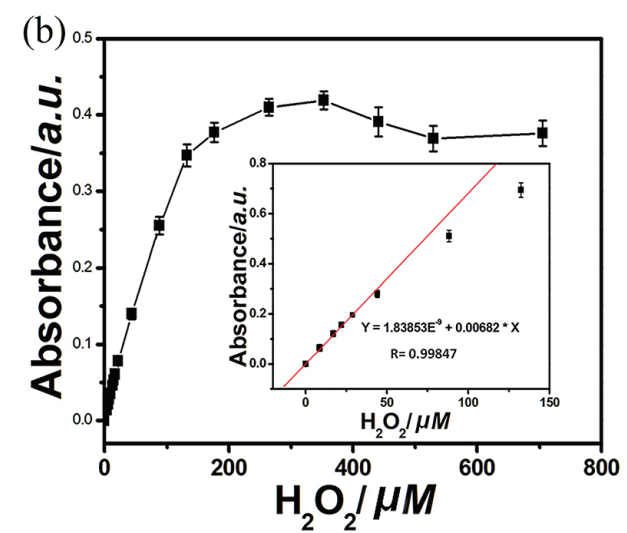

Figure 2. (a) Comparison of the absorbance intensity of the hemin/4-AAP/phenol system after interaction with different interfering components $\left(\mathrm{Zn}^{2+}\right.$, $\mathrm{CO}_{3}^{2-}, \mathrm{Mg}^{2+}, \mathrm{Cu}^{2+}, \mathrm{Ca}^{2+}, \mathrm{NO}_{3}^{-}, \mathrm{Fe}^{3+}, \mathrm{Cl}^{-}, \mathrm{PO}_{4}^{3-}, \mathrm{K}^{+}, \mathrm{SO}_{4}{ }^{2-}, \mathrm{Na}^{+}$, cysteine and lysine); (b) calibration plots of the hemin/4-AAP/phenol system toward $\mathrm{H}_{2} \mathrm{O}_{2}$ standards with various final concentrations (inset: corresponding linear plots). 
catalytic reaction of glucose; (iii) the cascade reaction was successfully carried out only in the simultaneous presence of glucose/GOx/hemin/4-AAP/phenol system. Hence, when the GOx was conjugated onto the detection antibody, the mimic enzyme-chromogenic strategy could be employed for the development of the sandwiched immunoassay by monitoring the change in the absorbance or color.

\section{Evaluation and characteristics of the $\mathrm{MECl}$ system}

In the MECI system, the cascade reaction mainly consisted of two steps: ( $i$ ) the catalytic reaction of GOx toward the glucose and (ii) the redox reaction between hydrogen peroxide and hemin in the 4-AAP/phenol system. Significantly, the $\mathrm{H}_{2} \mathrm{O}_{2}$ in the 4-AAP/phenol system toward hemin was specific and selectable. As shown in Figure 2a, a significant change in the absorptivity was observed at $505 \mathrm{~nm}$ with the $\mathrm{H}_{2} \mathrm{O}_{2}$ against 20-fold higher interfering components (e.g., $\mathrm{Zn}^{2+}, \mathrm{CO}_{3}{ }^{2-}, \mathrm{Mg}^{2+}, \mathrm{Cu}^{2+}, \mathrm{Ca}^{2+}, \mathrm{NO}_{3}^{-}$, $\mathrm{Fe}^{3+}, \mathrm{Cl}^{-}, \mathrm{PO}_{4}{ }^{3-}, \mathrm{K}^{+}, \mathrm{SO}_{4}{ }^{2-}, \mathrm{Na}^{+}$, cysteine and lysine). Although $\mathrm{Cu}^{2+}$ ion can cause the increase in the absorbance, the optical density was less. Hence, the hemin/4-AAP/ phenol system was used for the detection of $\mathrm{H}_{2} \mathrm{O}_{2}$. To perform the subsequent MECI, the system must have the ability to exactly differentiate the $\mathrm{H}_{2} \mathrm{O}_{2}$ with various concentrations. Thereupon, the analytical performance of the hemin/4-AAP/phenol system toward $\mathrm{H}_{2} \mathrm{O}_{2}$ with various concentrations was investigated under the same condition. As shown in Figure 2b, the absorbance increased with the increasing $\mathrm{H}_{2} \mathrm{O}_{2}$ concentration. Moreover, the calibration standards ranged from 12.5 to $132.37 \mu \mathrm{M}$ for $\mathrm{H}_{2} \mathrm{O}_{2}$, as shown in the inset in Figure $2 b$, and the detection limit of $\mathrm{H}_{2} \mathrm{O}_{2}$ was lowered to $3.8 \mu \mathrm{M}$. The results revealed that the system was feasible for quantitative monitoring of $\mathrm{H}_{2} \mathrm{O}_{2}$ in the sample. Toward bioactive GOx enzyme, however, the catalytic efficiency toward glucose relied on the catalytic time and temperature to some extent. Usually, the normal body temperature $\left(37^{\circ} \mathrm{C}\right)$ is suitable for enzymatic reaction. At this condition, the effect of different incubation times was monitored between GOx and glucose on the absorbance (10 $\mu \mathrm{L}$ of $1 \mathrm{mg} \mathrm{mL}^{-1} \mathrm{GOx}, 50 \mu \mathrm{L}$ of $1 \mathrm{mM}$ glucose, $70 \mu \mathrm{L}$ of $1.0 \mathrm{mg} \mathrm{mL}^{-1} 4$-AAP, $70 \mu \mathrm{L}$ of $0.12 \mathrm{M}$ phenol, $35 \mu \mathrm{L}$ of $0.05 \mathrm{mg} \mathrm{mL}^{-1}$ heme chloride solution and $350 \mu \mathrm{L}$ buffer $\left(\mathrm{K}_{2} \mathrm{HPO}_{4}: \mathrm{NaOH}, \mathrm{pH}=10.6\right)$ were used in this case). As indicated in Figure 3a, the absorbance increased within the initial $30 \mathrm{~min}$ and then tended to slightly decrease. The reason might be attributed to the fact that $\mathrm{H}_{2} \mathrm{O}_{2}$ was decomposed by light irradiation. Therefore, $30 \mathrm{~min}$ was selected for enzymatic reaction in this study. The enzymatic reactivity of GOx in the cascade reaction system was also studied. Various amounts of GOx were added to the system, and the absorption spectra were recorded. In this case, $50 \mu \mathrm{L}$ of $1 \mathrm{mM}$ glucose, $70 \mu \mathrm{L}$ of $1.0 \mathrm{mg} \mathrm{mL}^{-1} 4$-AAP, $70 \mu \mathrm{L}$ of $0.12 \mathrm{M}$ phenol, $35 \mu \mathrm{L}$ of $0.05 \mathrm{mg} \mathrm{mL}^{-1}$ heme chloride solution and $350 \mu \mathrm{L}$ buffer $\left(\mathrm{K}_{2} \mathrm{HPO}_{4}: \mathrm{NaOH}, \mathrm{pH}=10.6\right)$ were used for detection of $10 \mu \mathrm{L}$ of $\mathrm{GOx}$ with various concentrations. As seen from Figure $3 b$, the absorbance increased with the increment of GOx concentration in the sample. At the low-concentration (0-20 $\left.\mu \mathrm{g} \mathrm{mL}^{-1}\right) \mathrm{GOx}$, the absorbance exhibited a strong shift, and the LOD was ca. $1 \mu \mathrm{g} \mathrm{mL} \mathrm{L}^{-1} \mathrm{GOx}$. On the basis of these results, we might make a conclusion that the designed cascade reaction strategy based on the hemin/4-AAP/phenol system might be utilized for the determination of GOx by coupling with the change in the color and absorbance simultaneously. The results revealed that the system was feasible for quantitative monitoring of AFP in the sample, because its concentration changes can indirectly lead to the concentration changes of GOx.

Analytical performance of colorimetric immunoassay using the hemin/4-AAP/phenol system

To further investigate the capability of the MECI in the colorimetric immunoassay, the GOx-AuNP-RIgG
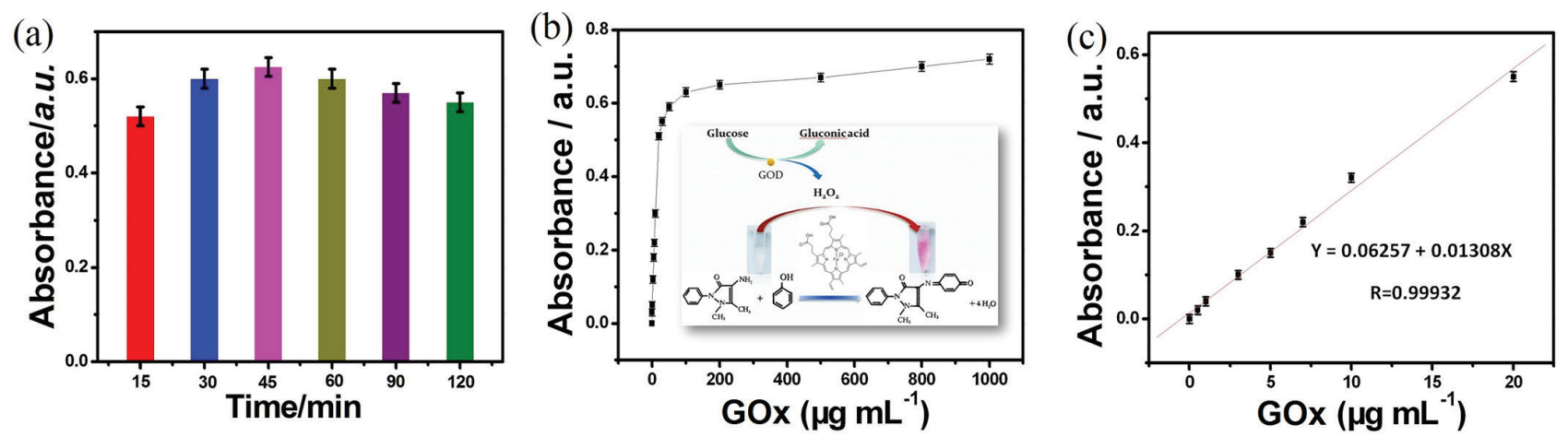

Figure 3. (a) The effect of different catalytic times between GOx and glucose on the absorbance intensity of the hemin/4-AAP/phenol system; (b) catalytic reactivity of the GOx with different concentrations in the hemin/4-AAP/phenol system; (c) calibration plots of the hemin/4-AAP/phenol system toward GOx with various concentrations. 
was employed as secondary antibody for the detection of target AFP with a sandwich-type immunoassay format on the MB-MIgM by using the hemin/4-AAP/phenol system. Under the optimal conditions, AFP standards with different concentrations were monitored based on the designed immunoassay protocol. As shown in Figures $4 \mathrm{a}$ and $4 \mathrm{~b}$, the increase of absorbance is proportional to the AFP antigen concentration in the range of $0.075-280.0 \mathrm{ng} \mathrm{mL}^{-1}$, and the LOD was $0.0247 \mathrm{ng} \mathrm{mL}^{-1}(\mathrm{~S} / \mathrm{N}=3)$, which was lower than the threshold value of total AFP in normal human serum (10 $\left.\mathrm{ng} \mathrm{mL}^{-1}\right) \cdot{ }^{36}$ The LOD was estimated according to the following equation: ${ }^{37}$

$\mathrm{LOD}=3.29\left(\sigma_{\mathrm{b} 1} / \mathrm{b}_{1}\right)$

where $b_{1}$ is the slope of the calibration line, meanwhile, $\sigma_{\mathrm{bl}}$ is the response dispersion at the blank level and it was obtained for 20 successive measurements of blank signal. Moreover, Table 1 showed the linear range and LOD of immunosensors with previous reports. ${ }^{38-43}$ Compared to other methods, the presented immunosensor has a relative large linear range and low LOD. As a result of the strong reaction in the hemin/4-AAP/phenol system, the improvement of the sensitivity might be attributed to the highly efficient mimic enzyme-chromogenic substrate system.

Reproducibility, selectivity and stability of the immunosensor

More favorably, the reproducibility and precision of the MECI was evaluated by calculating the intra- and interbatch coefficients of variation (CVs). Results revealed that the CVs of the intra-assay with this method were between 3.9 and $7.0 \%(n=5)$ in all cases. The batch-tobatch reproducibility of the MECI was also monitored by assaying $5 \mathrm{ng} \mathrm{mL}^{-1} \mathrm{AFP}$ (as an example) for six times within different days, and the obtained $\mathrm{CV}$ was about $8.0 \%$. The low CVs might be attributed to the specific antigen-antibody reaction and the strong interaction in the hemin/4-AAP/phenol system. Thus, the precision and reproducibility of the MECI was acceptable.

Further, the specificity of the MECI was also investigated toward other possible interfering substances, such as prostate-specific antigen (PSA), cancer antigen 125
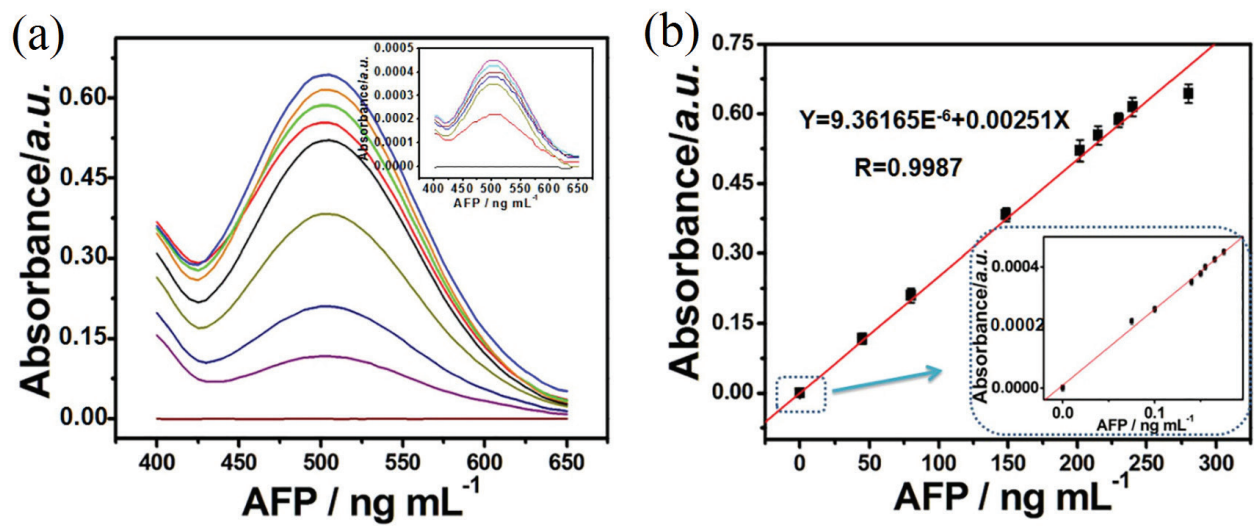

Figure 4. (a) Absorbance intensity of the MECI by coupling with the 4-AAP/phenol strategy toward different concentration AFP standards (inset: absorbance intensity toward low concentration AFP standards); (b) calibration plots of the MECI by coupling with the 4-AAP/phenol strategy toward different concentration AFP standards (inset: calibration plots toward low concentration AFP standards).

Table 1. Comparison of analytical properties of the immunoassay AFP immunosensors

\begin{tabular}{lccc}
\hline Method & Calibration range / $\left(\mathrm{ng} \mathrm{mL}^{-1}\right)$ & Detection limit $/\left(\mathrm{ng} \mathrm{mL}^{-1}\right)$ & Reference \\
\hline HRP/Au-PtNPs-MWCNTs/GCE & $0.5-20$ & 0.17 & 35 \\
Nanotube/DNA/Thi/nanoAu/GCE & $10.0-200.0$ & 0.04 & 36 \\
PLL-SWCNTs & $0.05-10.0$ and 10.0-50.0 & 0.011 & 37 \\
Ab-HRP/AFP/Ab/protein A/nanoAu/GCE & $5-80$ & 3.7 & 38 \\
SBA-15 & $1-90$ & 0.5 & 39 \\
NanoAu + BPPF + carbon paste & $0.5-80$ & 0.25 & 40 \\
Bead-based enzyme-chromogenic substrate system & $0.075-280$ & 0.0247 & this work
\end{tabular}

HRP: horseradish peroxidase; NP: nanoparticle; MWCNT: multi-walled carbon nanotube; GCE: glassy carbon electrode; DNA: deoxyribonucleic acid; Thi: thionine film; PLL-SWCNT: poly-L-lysine-single-walled carbon nanotube; AFP: $\alpha$-fetoprotein; SBA-15: a kind of mesoporous molecular sieve; $\mathrm{BPPF}_{6}: N$-butylpyridinium hexafluorophosphate. 
(CA 125), carcinoembryonic antigen (CEA), and human immunoglobulin $\mathrm{G}$ (HIgG). The reason for the use of these samples is that they usually coexist in the normal human serum. The comparative study was performed by measuring the low-concentration target AFP and high-concentration interfering components. As shown in Figure 5, higher absorbance was acquired with target AFP than those of other components. The results clearly indicated the high specificity of the MECI. The stability of the immunosensor was also tested, as shown in Figure S2 (SI section). The immunosensor was stored in PBS (pH 7.4) at $4{ }^{\circ} \mathrm{C}$ when not in use. The absorbance response of the electrodes only had a change of $4.2 \%$ after 20 days. This indicated the effective retention of the activity of the immobilized AFP antibody, and further confirmed that the reaction conditions of mimic enzyme are not harsh.

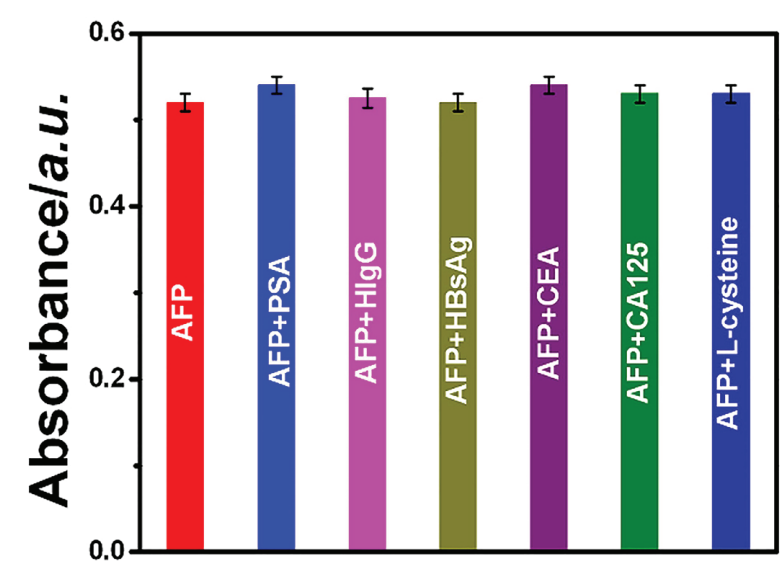

Figure 5. Specificity of the MECI against AFP $\left(10 \mathrm{ng} \mathrm{mL}^{-1}\right)$, PSA $\left(0.1 \mathrm{ng} \mathrm{mL}^{-1}\right)$, CEA $\left(10 \mathrm{ng} \mathrm{mL}^{-1}\right)$, CA $125\left(10 \mathrm{U} \mathrm{mL}^{-1}\right)$, and $\mathrm{HIgG}$ (10 ng mL $\mathrm{mL}^{-1}$ ).

\section{Real serum sample testing}

The immunosensor was used to detect real serum samples and the results were compared with those from the typical enzyme-linked immunoassays (ELISA). As shown in Table S1 (SI section), there was no significant difference between the two methods. Compared with the high cost and complex operation of the ELISA, the MECI has obvious advantages. Therefore, the immunoassay methodology might be potentially useful for determination of AFP in real serum samples.

\section{Conclusions}

In this work, based on mimic enzymatic formation of the chromogenic compound, we for the first time demonstrated the ability of unconventional ELISA product for exceptional application in the colorimetric immunoassay. The signal was amplified through an enzyme-catalyzed cascade reaction. Experimental results indicated that the visible color of the hemin/4-AAP/phenol system was successfully triggered by the catalytic product of GOx toward glucose. Compared with traditional enzyme-based colorimetric immunoassay, the mimic enzyme-based colorimetric immunoassay was of low cost, sensitive, rapid, stable and feasible. Moreover, the hemin/4-AAP/phenol system was not susceptible to interference and changed in the assay conditions during the color generation stage. Importantly, by controlling the target antibody, the mimic enzyme-based immunosensing system can be further extended for the qualitative and quantitative detection of other low-abundance proteins or biomarkers. Moreover, magnetic bead-based colorimetric immunoassay can be applied to miniaturized lab-on-a-chip devices, and it may open a new opportunity for protein diagnostic and biosecurity.

\section{Supplementary Information}

Supplementary information (stability of the MECI and UV-Vis absorption spectra of GOx + glucose + hemin + 4-AAP/phenol system, GOx + hemin + 4-AAP/phenol system, GOx + glucose + hemin, GOx + glucose + 4-AAP/ phenol system, and glucose + hemin $+4-\mathrm{AAP} /$ phenol system) is available free of charge at http://jbcs.sbq.org.br as PDF file.

\section{Acknowledgments}

This research is financially supported by the Special Research Project of Jiangxi University of Traditional Chinese Medicine (2016ZR002), National Natural Science Foundation of China (81460594), Natural Science Foundation of Jiangxi Province (20171BAB205092), Excellent Youth Foundation of Jiangxi Scientific Committee (20171BCB23045), Key Research and Development Project of Jiangxi Province (20171BBG70112).

All immunization tests were completed in aseptic processing room supported by Laboratory Animal Science and Technology Center, Jiangxi Universtiy of Traditional Chinese Medicine.

\section{References}

1. Bray, F.; Jemal, A.; Grey, N.; Ferlay, J.; Forman, D.; Lancet Oncol. 2012, 13, 790.

2. Jemal, A.; Bray, F.; Center, M. M.; Ferlay, J.; Ward, E.; Forman, D.; CA: Cancer J. Clin. 2011, 61, 69.

3. Chen, W.; Zheng, R.; Baade, P. D.; Zhang, S.; Zeng, H.; Bray, F.; Jemal, A.; Yu, X. Q.; He, J.; CA: Cancer J. Clin. 2016, 66, 115. 
4. Etzioni, R.; Urban, N.; Ramsey, S.; McIntosh, M.; Schwartz, S.; Reid, B.; Radich, J.; Anderson, G.; Hartwell, L.; Nat. Rev. Cancer 2003, 3, 243.

5. Winter, J. M.; Yeo, C. J.; Brody, J. R.; J. Surg. Oncol. 2013, 107, 15.

6. Feng, T.; Qiao, X.; Wang, H.; Sun, Y.; Qi, Y.; Hong, C.; J. Mater. Chem. B 2016, 4, 990.

7. Sánchez, J. L.; Henry, O. Y.; Joda, H.; Solnestam, B. W.; Kvastad, L.; Johansson, E.; Akan, P.; Lundeberg, P.; Lladach, N.; Ramakrishnan, D.; Biosens. Bioelectron. 2016, 82, 224.

8. Jeong, S.; Park, J.; Pathania, D.; Castro, C. M.; Weissleder, R.; Lee, H.; ACS Nano 2016, 10, 1802.

9. Hu, W.; Lu, Z.; Liu, Y.; Chen, T.; Zhou, X.; Li, C. M.; Lab Chip 2013, 13, 1797.

10. Mizusawa, K.; Takaoka, Y.; Hamachi, I.; J. Am. Chem. Soc. 2012, 134, 13386.

11. Xu, S.; Liu, Y.; Wang, T.; Li, J.; Anal. Chem. 2011, 83, 3817.

12. Huang, P.; Zheng, W.; Zhou, S.; Tu, D.; Chen, Z.; Zhu, H.; Li, R.; Ma, E.; Huang, M.; Chen, X.; Angew. Chem., Int. Ed. 2014, $53,1252$.

13. Stern, E.; Vacic, A.; Rajan, N. K.; Criscione, J. M.; Park, J.; Ilic, B. R.; Mooney, D. J.; Reed, M. A.; Fahmy, T. M.; Nat. Nanotechnol. 2010, 5, 138.

14. Rica, R. D. L.; Stevens, M. M.; Nat. Nanotechnol. 2012, 7, 821.

15. Peng, M. P.; Ma, W.; Long, Y. T.; Anal. Chem. 2015, 87, 5891.

16. Jang, H. R.; Wark, A. W.; Baek, S. H.; Chung, B. H.; Lee, H. J.; Anal. Chem. 2014, 86, 814.

17. Tang, L.; Casas, J.; Venkataramasubramani, M.; Anal. Chem. 2013, $85,1431$.

18. Hu, W.; He, G.; Chen, T.; Guo, C. X.; Lu, Z.; Selvaraj, J. N.; Liu, Y.; Li, C. M.; Chem. Commun. 2014, 50, 2133.

19. Tang, D.; Zhang, B.; Tang, J.; Hou, L.; Chen, G.; Anal. Chem. 2013, 85, 6958.

20. Chon, H.; Lee, S.; Yoon, S. Y.; Lee, E. K.; Chang, S. I.; Choo, J.; Chem. Commun. 2013, 50, 1058.

21. Zhang, W.; Ma, W.; Long, Y. T.; Anal. Chem. 2016, 88, 5131.

22. Huang, X.; Zhan, S.; Xu, H.; Meng, X.; Xiong, Y. H.; Chen, X. S.; Nanoscale 2016, 8, 9390.

23. Martić, S.; Gabriel, M.; Turowec, J. P.; Litchfield, D. W.; Kraatz, H. B.; J. Am. Chem. Soc. 2012, 134, 17036.
24. Liu, W.; Cassano, C. L.; Xu, X.; Fan, Z. H.; Anal. Chem. 2013, 85, 10270.

25. Gao, Z.; Xu, M.; Hou, L.; Chen, G.; Tang, D.; Anal. Chem. 2013, 85, 6945.

26. Chen, D.; Sarikaya, N. A.; Gunn, H.; Martin, S. W.; Young, J. D.; Clin. Chem. 2001, 47, 747.

27. Wilson, R. M.; Danishefsky, S. J.; J. Am. Chem. Soc. 2013, 135, 14462.

28. Lin, H.; Liu, Y.; Huo, J.; Zhang, A.; Pan, Y.; Bai, H.; Jiao, Z.; Fang, T.; Wang, X.; Cai, Y.; Anal. Chem. 2013, 85, 6228.

29. Song, Y.; Wei, W.; Qu, X.; Adv. Mater. 2011, 23, 4215.

30. Zhang, B.; Tang, D.; Goryacheva, I. Y.; Niessner, R.; Knopp, D.; Chemistry 2013, 19, 2496.

31. Huang, M. X.; Zhu, M.; Shen, H. X.; Microchim. Acta 1998, $128,87$.

32. Yang, Z.; Qian, J.; Yang, X.; Jiang, D.; Du, X.; Wang, K.; Mao, H.; Wang, K.; Biosens. Bioelectron. 2015, 65, 39.

33. Zhang, L. Y.; Fan, C.; Liu, M.; Liu, F. J.; Bian, S. S.; Du, S. Y.; Zhu, S. Y.; Wang, H.; Sens. Actuators, B 2018, 266, 543.

34. Chabner, B. A.; Lynch Jr., T. J.; Longo, D. L.; Harrison's Manual of Oncology, $1^{\text {st }}$ ed.; McGraw-Hill Medical Publishing Division: USA, 2008.

35. Song, Y.; Chen, J.; Liu, H.; Song, Y.; Xu, F.; Tan, H.; Wang, L.; Electrochim. Acta 2015, 158, 56.

36. Su, B.; Tang, D.; Li, Q.; Tang, J.; Chen, G.; Anal. Chim. Acta 2011, 692, 116.

37. Castillo, M. A.; Castells, R. C.; J. Chromatogr. A 2001, 921, 121.

38. Li, Y.; Yuan, R.; Chai, Y.; Song, Z.; Electrochim. Acta 2011, 56, 6715.

39. Ran, X. Q.; Yuan, R.; Chai, Y. Q.; Hong, C. L.; Qian, X. Q.; Colloids Surf., B 2010, 79, 421.

40. Wang, Y.; Qu, Y.; Ye, X. X.; Wu, K.; Li, C.; J. Solid State Electrochem. 2016, 20, 2217.

41. Giannetto, M.; Elviri, L.; Careri, M.; Mangia, A.; Mori, G.; Biosens. Bioelectron. 2011, 26, 2232.

42. Lin, J.; Wei, Z.; Mao, C.; Biosens. Bioelectron. 2011, $29,40$.

43. Ding, C.; Zhao, F.; Ren, R.; Lin, J. M.; Talanta 2009, 78, 1148.

Submitted: June 21, 2018

Published online: November 8, 2018 